\title{
A photoelectric shock scrambler
}

\author{
ROBERT ADAMSON AND LEVI MCNAB, FLORIDA \\ ATLANTIC UNIVERSITY
}

A shock scrambler using photoelectric conductors which operate relays is described. The scrambler has advantages of low cost and reliable operation.

Typically, difficulty of construction and problems of mechanical wear characterize shock scramblers. The present design represents an effort to achieve reliable operation with an easily built and inexpensive device. Two models of the scrambler have been built and are currently in operation.

The scrambler consists of a set of photoelectric conductors mounted behind concentric, non-overlapping slits on a turning wheel (see Fig. 1). As light passes through each slit, it reduces the resistance of one of the conductors from its dark value, thus allowing current flow to a control relay in series with the conductor.

The disk shown in Fig. 1 could be constructed of any opaque material. In the prototype, $1 / 8$ in. masonite was used for a 6 in. wheel diameter. The slits were $1 / 4$ in. wide.

The block holding the photoconductors also could be wood or any easily worked material. The present model used a block of opaque Plexiglas, 1 in. square. The photocells were mounted in $1 / 2$ in. holes drilled horizontally halfway into the block. The light ports for each cell were $1 / 32$ in. holes drilled through the block. The cells were separated by $3 / 4 \mathrm{in}$. at the centers.

Use of a relatively insensitive photoconductor (Sylvania, Type $\mathrm{T}-4 \mathrm{CdS}$, Model 8347) allows separation between the disk and the photocell block of about $1 / 4$ in. with no ambient light problems. The above mentioned conductor has a dark $(1 \mathrm{ft}-\mathrm{c})$ resistance of $30,000 \mathrm{ohms}$ which drops to $300 \mathrm{ohms}$ at $120 \mathrm{ft}$-c. Other more sensitive conductors, such as the Sylvania model $345(10,500$ ohms at $1 \mathrm{ft}-\mathrm{c}$ to $20 \mathrm{ohms}$ at $120 \mathrm{ft}-\mathrm{c}$ ) may be used, but greater care is necessary to mask ambient light. In either event it is necessary to tape over the back of the mounting hole so that light does not impinge on the cell from the rear.

The drive motors used in the models were $115 \mathrm{~V}$ ac synchronous motors (Holtzer-Cabot) with a gear train, allowing variable speed operation from $0.5 \mathrm{rps}$ to $60 \mathrm{rps}$. In view of the successful operation of the scrambler within this range, any drive system such as that afforded by a single speed motor should be adequate.

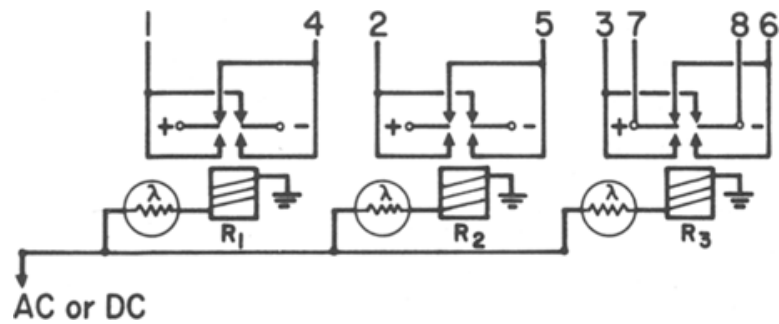

Fig. 2. Circuit diagram of the scrambler.
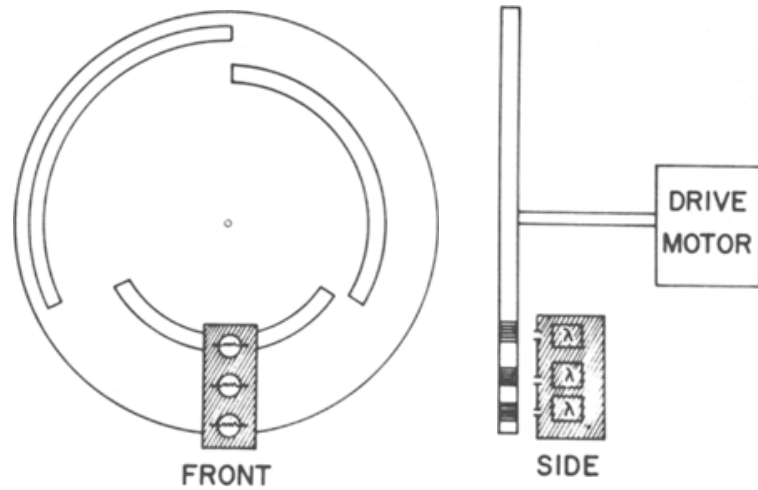

Fig. 1. Construction of the photoelectric control device.

Figure 2 shows the circuit diagram for the scrambler. Each photoelectric conductor is placed in series with a control relay which reverses polarity to two bars on a grid. As shown, when Bar 1 is negative, Bar 4 is positive; however, the pattern may be varied to any other combination of bars. With three relays, as in the present model, six bars change polarity with photoelectric operation, and up to six bars may be operated at constant polarity.

With a firing order of 1-2-3 for the relays, the following polarity pattern obtains for one revolution of the motor:

Bars

$\begin{array}{llllllllll} & & 1 & 2 & 3 & 4 & 5 & 6 & 7 & 8 \\ \text { Firing } & 1 & + & - & - & - & + & + & + & - \\ \text { Order } & 2 & - & + & - & + & - & + & + & - \\ & 3 & - & - & + & + & + & - & + & -\end{array}$

Altnougn the inree-relay device has proved ettective in preventing adaptive behavior on the part of rats, it is conceivable that they could learn to bridge bars of the same polarity. The design, however, allows for the inclusion of a greater number of conductors and relays to a point where bridging would be impossible.

Both ac and dc relays have been tested and found equally successful. The ac relays were Guardian, Series 200, and Potter and Brumfield, type GM $11 \mathrm{~A}$. These coils are rated at $115 \mathrm{~V}$ ac. A $24 \mathrm{~V}$ dc relay (Potter and Brumfield, GA11D) works with a dc power supply. All relays are double-pole, double-throw types, and, within the range of speeds mentioned above, relay switching speed does not constitute a constraint.

Relay noise could constitute a problem for certain experiments. For one of the models, the relay units have been separately housed from the drive-photoconductor unit and placed in a separate room with multiple-strand connector wire bridging the components.

The scrambler has been in operation for over three months with no breakdowns. The component cost, exclusive of the drive motor, is under $\$ 20.00$.

NOTE

1. This research was supported by the Air Force Office of Scientific Research, Grant No. 1163-66. 